\title{
Anticentriolar autoantibodies in children with central nervous system manifestations of Mycoplasma pneumoniae infection
}

\author{
Nevio Cimolai, Diana Mah, Elke Roland
}

\begin{abstract}
Serum samples from 49 children with acute Mycoplasma pneumoniae infection were screened for the presence of antibodies to mitotic spindle apparatus. None of these serum samples showed such antibodies at a screening dilution of $1: 40$, though anticentriolar antibodies at titres of 1:320 were observed in two children with acute cerebellar dysfunction. Anticentriolar antibodies may play a part in the pathogenesis of CNS disease associated with $M$ pneumoniae infection.
\end{abstract}

$(\mathcal{F}$ Neurol Neurosurg Psychiatry 1994;57:638-639)

Although Mycoplasma pneumoniae infection is generally associated with respiratory symptoms, a spectrum of non-respiratory manifestations has been described. Direct infection and the related immune response are believed to be responsible for the pulmonary disease, but it is unclear whether similar mechanisms of pathogenesis are responsible for disease outside the respiratory system. It is probable that the non-respiratory manifestations are secondary to the effects of autoantibody formation. This explanation has been proposed in view of the relative infrequency of $M$ pneumoniae isolation outside the respiratory tract and in view of reports of associated autoantibodies which include cold red blood cell agglutinins and antibodies to brain, smooth muscle, mitotic spindle apparatus, intermediate filaments, and glycolipids. ${ }^{1-5}$

In a study of the pathophysiological basis for non-respiratory manifestations of $M$ pneumoniae infection in children, we studied the occurrence of antibodies to mitotic spindle apparatus in this age group. We were unable to confirm the presence of these antibodies at screening dilutions. We report, however, two patients with neurological disease associated with $M$ pneumoniae infection whose serum samples contained high titres of anticentriolar antibodies, and discuss the possible significance of these findings in the pathogenesis of CNS disease.

\section{Methods and results}

Serum samples from 49 children (aged 18 months to 16 years) with $M$ pneumoniae infection were assayed for IgG antibodies to mitotic spindle apparatus by indirect immunofluorescence. Infection was confirmed by complement fixation serology and IgM immunoblotting. ${ }^{6}$ Patient serum samples were screened at a 1:40 dilution on Hep-2 and HeLa cells. Hep-2 cells were acquired commercially (Inova Diagnostics Inc., California) in prepackaged multiwell slides and $\mathrm{HeLa}$ cells were grown on $8 \mathrm{~mm}$ glass coverslips in our laboratory. Antihuman IgG fluorescein isothiocyanate-labelled conjugates were obtained from either Inova Diagnostics or Jackson Immunoresearch Laboratories, Inc. (Pennsylvania).

None of the serum samples in our 49 children yielded positive assays for antibody to mitotic spindle apparatus at the screening dilution. Serum samples from two patients, however, had evidence of anticentriolar antibodies. In these two cases subsequent assays were performed on serial twofold dilutions and the maximum titres were determined as 1:320. The two patients developed neurological abnormalities after the onset of respiratory symptoms. Only one other child had clinical evidence of CNS disease but the assessment of this child was complicated by the documentation of rhinovirus in the nasopharynx and positive Epstein-Barr virus serology. The latter child had a mild encephalopathy (visual hallucinations) but did not manifest cerebellar dysfunction. Furthermore, there was a temporal association between the encephalopathy and the administration of a narcotic analgesic. None of the other 46 patients had clinical neurological abnormalities or evidence of anticentriolar antibodies.

\section{PATIENT 1}

An 8-year-old girl was admitted to hospital with acute headache, unsteady gait, slurred speech, and deterioration in her handwriting. Two weeks earlier she had developed a persistent cough. The neurological symptoms began two days before admission. In the initial examination the patient was afebrile and did not have evidence of meningeal irritation. She had a macular erythematous rash on the anterior trunk. The patient manifested slurred speech, dysmetria, and ataxia. Her white blood cell count was $6.8 \times 10^{\%} / 1$. A chest radiograph showed right middle and 
right lower lobe atelectasis. A CT scan of her head was normal. Examination of her CSF gave a white blood cell count of $9 \times 10^{6} / 1$ (lymphoid predominance), a red blood cell count of $1 \times 10^{6} / 1$, glucose $3.1 \mathrm{mmol} / 1$ (serum 4.9), and protein $0 \cdot 11 \mathrm{~g} / 1$. A serum sample drawn on the second day after admission to hospital gave a complement fixation titre of 1/256 for $M$ pneumoniae; immunoblotting of IgM antibodies to P1 was strongly positive. The patient was treated with erythromycin. The rash and neurological signs resolved within one week.

\section{PATIENT 2}

A 13-year-old boy developed an upper respiratory tract infection which was initially treated with amoxicillin. Seven days later he developed pneumonia and was treated with intravenous cefuroxime at another hospital. A diffuse maculopapular rash erupted and the antibiotic was discontinued. Five days later he developed confusion, dysmetria, dysarthria, and a constant tremor of the limbs, and was transferred to our hospital. Within 24 hours of admission the patient had a single prolonged generalised tonic-clonic seizure and required phenytoin, phenobarbital, diazepam, and paraldehyde along with intensive care. He was also treated with chloramphenicol and acyclovir. His white blood cell count was $8 \cdot 4 \times 10^{9} / 1$. Haematological indices and indicators of electrolyte status, renal function, and liver function were considered normal. A CSF sample had a white blood cell count of $21 \times$ $10^{6} / 1$ (predominantly lymphocytes), a red blood cell count of $63 \times 10^{6} / 1$, glucose $6 \cdot 2$ $\mathrm{mmol} / 1$ (serum 8.5), and protein $0.92 \mathrm{~g} / \mathrm{l}$. Viral culture of his CSF was negative. An EEG was severely abnormal with diffuse slowing of background activity. A CT scan showed morphological changes in the midbrain, suggesting an effect which was consistent with demyelination or an inflammatory process, and he was treated with corticosteroids for five days. The cerebellar signs resolved gradually during the next 10 days. The complement fixation titre to $M$ pneumoniae was $1 / 256$ and immunoblotting for $\operatorname{IgM}$ antibody to $\mathrm{Pl}$ was strongly positive.

\section{Discussion}

The spectrum of neurological manifestations of $M$ pneumoniae infection is diverse and includes meningitis, encephalitis, cranial nerve dysfunction, hemiplegia, transverse myelitis, cerebellar ataxia, peripheral neuropathy, and psychosis. ${ }^{7}$ Based on the rare documentation of direct isolation of $M$ pneumoniae from the CNS and given the delay in onset, it has been postulated that an immunological process (especially autoimmune) may play a part in the pathogenesis. This is supported by neuropathological obser- vations of demyelination and perivenous inflammation (that is, acute disseminated encephalomyelitis), ${ }^{7}$ and signal changes consistent with demyelination documented by MRI. ${ }^{8}$ Although antibodies to brain have been reported in patients with $M$ pneumoniae infection, their incidence is not increased in patients with neurological symptoms. Antibody to sialosyllactoaminyl paragloboside has also been reported in one patient with polyradiculopathy. ${ }^{5}$

Anticentriolar autoantibodies are rarely seen in the titres which we have found for our patients. ${ }^{9}$ Most patients with such antibodies have had features of scleroderma-like illnesses. It is of interest that the enzyme enolase has been proposed as one target of anticentriolar antibodies and that a neuronalpredominant enolase isoenzyme exists. It is also of interest that IgG antibodies to mitotic spindle apparatus in titres greater than or equal to 1:40 did not exist in our sample of $M$ pneumoniae-infected children. Such infrequency is in contrast with the report of Lind et al. ${ }^{4}$

Although we might initially ascribe our findings of anticentriolar antibodies to an epiphenomenon, it is remarkable that these two patients showed manifestations of CNS disease. Furthermore, the two patients manifested cerebellar dysfunction, which occurs in only a few patients with $M$ pneumoniae-associated neurological disease. ${ }^{10}$

These observations suggest that the role of anticentriolar autoantibodies in the pathogenesis of $M$ pneumoniae-associated CNS disease deserves further investigation. Crucial to this study will be the prospective recognition of patients with infection, and we propose that rapid immunoblotting for $\operatorname{IgM}$ antibodies to $\mathrm{P} 1$ is the laboratory tool that will currently best facilitate such identification.

1 Biberfeld G. Antibodies to brain and other tissues in cases of Mycoplasma pneumoniae infection. Clin Exp Immunol 1971;8:319-33.

2 Biberfeld G, Sterner G. Smooth muscle antibodies in Mycoplasma pneumoniae infection. Clin Exp Immunol 1976;24:287-91

3 Bretherton L, Toh BH, Jack I. IgM autoantibody to intermediate filaments in Mycoplasma pneumoniae infections. Clin Immunol Immunopathol 1981;18:425-30.

4 Lind K, Hoier-Madsen M, Wiik A. Autoantibodies to the mitotic spindle apparatus in Mycoplasma pneumoniae disease. Infect Immun 1988;56:714-5.

5 Inuzaka T, Miyatani N, Baba $\mathrm{H}$, et al. IgM binding to sialosyllactosaminylparagloboside in a patient with polyradiculoneuropathy due to Mycoplasma pneumopolyradiculoneuropathy due to Mycoplasma
niae infection. Acta Neurol Scand 1988;78:53-7.

6 Cimolai N, Cheong ACH. IgM anti-P1 immunoblotting: a standard for the rapid serologic diagnosis of Mycoplasma pneumoniae infection in pediatric care. Chest 1992;102:477-81.

7 Behan PO, Feldman RG, Segerra JM, Draper IT. Neurological aspects of mycoplasmal infection. Acta Neurol Scand 1986;74:314-22.

8 Francis DA, Brown A, Miller DH, Wiles CM, Bennett ED, Leigh N. MRI appearances of the CNS manifestations of Mycoplasma pneumoniae: a report of two cases. f Neurol 1988;235:441-3.

9 Rattner JB, Marin L, Waisman DM, Johnstone SA, Fritzler MJ. Autoantibodies to the centrosome (centriole) react with determinants present in the glycolytic enzyme enolase. F Immunol 1991;146:2341-4.

10 Ponka A. Central nervous system manifestations associated with serologically verified Mycoplasma pneumoniae infection. Scand f Infect Dis 1980;12:175-84. 